\title{
Evaluation of Agile Software Projects in the Public Sector: A Literature Review
}

\author{
Marcelo Carvalho Fernandes ${ }^{1}$, Antonio Juarez Alencar ${ }^{1 *}$, Eber Assis Schmitz ${ }^{1}$, \\ Monica Ferreira da Silva ${ }^{1}$, Petros Sotirios Stefaneas ${ }^{2}$ \\ 1 The Tércio Pacitti Institute, Federal University of Rio de Janeiro, Brazil. \\ ${ }^{2}$ National Technical University of Athens, Greece. \\ * Corresponding author. Tel.: +55 21 3938-3224; email: antonio.juarez.alencar@gmail \\ Manuscript submitted November 10, 2015; accepted January 8, 2016. \\ doi: 10.17706/jsw.11.3.312-325
}

\begin{abstract}
In recent years, agile methods have become a subject of great interest for civil servants. Not only does their use facilitate the deeper involvement of product owners, but it also encourages the early appropriation of many benefits. Since governments are nonprofit organizations, the success of software projects in the public sector relies mostly on the evaluation of the intangible benefits they provide. Nevertheless, everything costs something. Therefore, the evaluation of agile projects in the public sector should take a balanced view of both the tangible and intangible benefits they provide. This paper reviews the existing literature on the evaluation of agile projects in the public sector and analyzes the methods that have been proposed so far. Moreover, it explains the shortcomings of these methods and indicates opportunities for further research and development.
\end{abstract}

Key words: Agile methods, project management, investment analysis, intangible benefits, public sector, research opportunities.

\section{Introduction}

According to the Gartner Group Analyst Susan Moore, in recent years the public sector has been facing a regime of major fiscal austerity [1]. In spite of this, investments in information and communication technology (ICT) have remained substantial, accounting for considerable sums of money. For instance, in 2013 the American government alone invested around 76 billion dollars in ICT. This is twice as much as the turnover of BHP Billiton, one of the top three mining companies in the world [2], [3]. Estimates indicate that the public sector invested almost half a trillion dollars in ICT around the world in that year [1]. Hence, government is among the major investors in ICT worldwide [4].

The way money is invested in ICT has changed considerably over the years. Initially it favored operational goals, such as allowing calculations to be done with precision and speed. Subsequently, it was used to reduce running costs through process automation and to improve decision making at managerial level [5]. More recently, ICT investments have been used to obtain strategic advantage, enhance security and gather intelligence [6].

In addition, ICT has been used to facilitate communication among government agencies, between government and civil servants, and between government and its citizens. The term electronic government or e-gov for short is used to refer to ICT investments that support these ideas [7].

All of this has increased the number and complexity of ICT projects run by a variety of organizations in 
the private and public sectors. It should be noted that a considerable amount of ICT projects involves the development of software. As a consequence, concepts, methods, tools and techniques capable of increasing software quality have become important for decision makers in both sectors [8].

In recent years, software developers in the private sector have adopted agile methods as a means of providing continuous delivery of software units. In addition, the use of these methods increases the involvement of product owners in the development process. In the agile method vocabulary product owners are those who are in charge of requirement definition [9].

It is claimed by many that agile software methods are able to increase software quality. This is achieved by allowing product owners to get a better understanding of the product being built earlier in the development process [10]. Not surprisingly, agile methods of software development have also become a subject of interest for civil servants [10]-[12].

According to Prof. Milton Friedman (1912 - 2006), the celebrated American economist: "There's no such thing as a free lunch" [13]. Therefore, ICT projects in the public sector need capital to be run. However, despite all the qualifications and experience that civil servants may have, the decision of when and where to invest in ICT is still a challenging endeavor [14].

What makes the analysis of such investments so difficult are not only their consequences, which are considerable in the modern world. There is also the need to take into account a number of service providers and a variety of commercial of-the-shelf software. Not to mention the diversity of development platforms and new technology that reaches the marketplace with increasing frequency. Moreover, ICT investments in the public sector tend to yield a substantial amount of intangible benefits, which are hard to quantify [15].

All of this has motivated academics and practitioners to put forward proposals for evaluating ICT investments in the public sector. Most of the proposals presented so far are adaptations of methods that have been successfully applied to the private sector. Nevertheless, the public and private sectors are significantly distinct in their objectives, cultures and management structures. Therefore, these methods tend to ignore important aspects of ICT investments that limit their use by government organizations [16], [17].

A recent report published by the US Government Accountability Office [11] stated that only $9 \%$ of the projects in the US public sector were delivered within their budgets. This same report shows that most ICT projects not only cost more than planned, but also take longer than expected. For this reason, the public sectors in both the US and around the world are paying more attention to the effective cost management of the ICT projects they run [18], [19].

This paper carries out a literature review on the evaluation of agile projects in the public sector. It aims to promote the development and refinement of better methods for analyzing such investments. Therefore, it identifies the methods that have been proposed so far and indicates their shortcomings. In addition, it highlights opportunities for future research and development.

This paper is intended to be a source of information for both academics and industry professionals. In this respect, it is important to mention that no previous paper has performed a similar literature review. In addition, no other paper has presented the opportunities for research and development that this paper does (see Sections 3 and 4 in this regard). As a result, it presents a new contribution to the advancement of the evaluation of agile projects in the public sector.

The remainder of this paper is organized as follows. Section 2. presents a summary of agile methods, concepts and ideas, which are required to more easily understand the content of the subsequent sections. Section 3. discusses the strategy used to identify the research opportunities presented in this paper. Section 4. introduces these research opportunities. Finally, Section 5. presents the conclusions of this work. 


\section{Agile Software Projects}

The last years of the twentieth century witnessed a considerable change in the principles and practices of software development. From extensive and detailed planning before coding, practitioners started favoring short cycles of quick planning and minimal coding. As a result, the heavyweight methods for developing software used so far gave way to a multitude of lightweight methods that delivered working features rapidly [20].

In 2001 all these new principles and practices were organized into an integrated overview by the Agile Manifesto [21]. Henceforward, a software project is called agile if it follows the principles established by the manifesto, i.e.

- The highest priority of an agile team is to satisfy customers through early and continuous delivery of valuable software,

- Changing requirements are welcome, even late in the development process,

- Working software should be delivered frequently,

- Business people and developers must work together throughout the project on a daily basis,

- Projects must be built around motivated individuals,

- Face-to-face conversation is frequently the most efficient and effective method of conveying information,

- Working software parts is the primary measure of progress,

- Agile processes provide a sustainable development environment,

- Continuous attention to technical excellence enhances agility,

- Maximizing the amount of work already done is essential,

- The best solutions emerge from self-organizing teams, and

- At regular intervals the agile team should reflect on how to become more effective, making the necessary adjustments.

It is frequently the case that researchers and practitioners claim that the following benefits can be appropriated by using agile methods:

- Prioritizing the work to be carried out according to the product owner's perception of relevance increases the business value of the project as a whole,

- Continuous delivery of working features, favoring earlier feedback from clients and users, and

- Greater flexibility in planning and implementation, making change management easier.

All of this is expected to promote client and user involvement in the project, increasing communication, facilitating cooperation and reducing risk [22].

\section{Literature Review}

In order to identify research opportunities that are pertinent to the objectives of this paper, a literature review on potentially relevant work was carried out. It was performed from April to June 2014, and then updated in May 2015.

This literature review involves the selection of well-known repositories of scientific and technical work, the identification of search terms to be applied to these repositories, and strategies to analyze selected work. All of this follows the ideas of [23] and [24] on the systematic review of literature.

\subsection{Repositories}

Table 1 presents the repositories considered in the literature review. It should be emphasized that these repositories index the vast majority of significant computer-science research around the world. 
Table 1. Repositories Used for the Literature Review

\begin{tabular}{|l|}
\hline Repository \\
\hline \hline ACM Digital Library \\
\hline Google Scholar \\
\hline IEEE Xplore Digital Library \\
\hline JSTOR \\
\hline Science Direct \\
\hline Scopus \\
\hline Springer Link \\
\hline Web of Science \\
\hline
\end{tabular}

Google Scholar has been recently criticized with regards to its usefulness as a repository of scientific and technical work [25]. Nevertheless, the authors of this paper have decided to use it as a source of potentially relevant information. This decision is based upon the fact that Google Scholar is the only open access repository that indexes books, dissertations, theses, technical reports and unpublished works. All of this is expected to increase the quality of the results presented in this paper.

\subsection{Search Terms}

Consistent with the goals of this paper, the search terms used to consult the repositories presented in Table 1 seek to identify works in the intersection of the following areas:

- Investment analysis,

- Intangible benefits and

- Agile software projects.

These search terms are presented in Table 2.

Table 2. Search Terms

\begin{tabular}{|c|l|}
\hline$\#$ & Term \\
\hline \hline 1 & Investment \\
\hline 2 & Analysis \\
\hline 3 & Appraisal \\
\hline 4 & Assessment \\
\hline 5 & Evaluation \\
\hline 6 & Valuation \\
\hline 7 & Intangible Benefit \\
\hline 8 & Intangible Value \\
\hline 9 & Agile Approach \\
\hline 10 & Agile Development \\
\hline 11 & Agile Manifesto \\
\hline 12 & Agile Management \\
\hline 13 & Agile Method \\
\hline 14 & Agile Methodology \\
\hline 15 & Agile Project \\
\hline 16 & Agile Software \\
\hline & (1 OR 2 OR 3 OR 4 OR 5 OR 6) AND \\
\hline 17 & (7 OR 8) AND \\
\hline & (9 OR 10 OR 11 OR 12 OR 13 OR 14 OR 15 OR 16) \\
\hline
\end{tabular}

It should be noted that the terms in Table 2 derive from well-established concepts from finance [26], economics [27], benefit analysis [28] and ICT [29]. For example, terms from 1 to 6 target works related to investment analysis. Terms number 7 and 8 aim to find works related to any kind of projects that yield intangible benefits. Terms 9 to 16 address works in the area of agile software projects. Finally, term 17 concatenates all these search terms into a single logical expression.

Nonetheless, according to Uyar [30] Google Scholar has a peculiar way of dealing with the singular and 
plural forms of words. As a result, it is not always the case that by providing the singular form of a word one is able to select papers that only contain its plural form.

Therefore, in order to be certain that all relevant papers are properly selected, the plural forms of the terms introduced in Table 2 were also used to produce a new term 17. This new term is identical to the old one in structure. However, instead of using just the singular form of the search terms, it uses both their singular and plural forms.

It is this new term 17 that is used to search the repositories presented in Table 1 for relevant work. It should be noted that it broadens the search, allowing relevant work to contain both the singular and plural forms of the search terms introduced in Table 2. Furthermore, the new term 17 ensures the selection of works related to the evaluation of agile software projects that yield intangible benefits.

Observe that intangibles are of particular interest for projects that are run in the public sector. Democratic governments are non-profit organizations whose sole purpose is the improvement of people's well-being. While some of these improvements can be measured by social and economic indexes, the vast majority of them are intangibles that are hard to quantify. As a result, the intangible benefits yielded by ICT investments in the public sector have to be taken into account when determining their worth [4].

\subsection{Search Execution}

When performing the search in the repositories presented in Table 1, no constraints were imposed on the publication date of related work. Table 3 presents some statistics on the works returned by the search process.

Table 3. Hits Per Repository

\begin{tabular}{|l|r|r|}
\hline Repository & Hit count & $\mathbf{\%}$ \\
\hline \hline ACM Digital Library & 23 & 4.0 \\
\hline Google Scholar & 421 & 74.1 \\
\hline IEEE Xplore Digital Library & 49 & 8.6 \\
\hline JSTOR & 13 & 2.3 \\
\hline Science Direct & 16 & 2.8 \\
\hline Scopus & 13 & 2.3 \\
\hline Springer Link & 13 & 2.3 \\
\hline Web of Science & 12 & 2.1 \\
\hline Wiley Online Library & 8 & 1.4 \\
\hline \hline Grand total & $\mathbf{5 6 8}$ & $\mathbf{1 0 0 . 0}$ \\
\hline
\end{tabular}

\subsection{Selection Criteria}

Initially, the titles, keywords, abstracts and publication sources of the 568 references were analyzed. As a result, duplicated references, works that have not yet been published and works that are not related to the evaluation of agile software projects that yield intangible benefits were eliminated.

It should be mentioned that Google Scholar may return references to books in its search results. As books tend not to provide an abstract or keywords that summarize their contents, a different approach has to be adopted as an exclusion criterion. Book references returned by Google Scholar can be searched using Google Books. Therefore, each occurrence of the terms presented in Table 2 has been individually analyzed with the support of that tool. Books with no relevance to the goals of this article were eliminated.

Note that out of the initially selected 568 references to scientific and technical works, 3 have not been published yet and 306 were duplicated. From the remaining 259 references, 237 were found not to be connected to the goals of this article. Therefore, only 22 works survived the initial selection criteria.

Next, the full text of the 22 remaining works were read and subjected to the selection criteria presented in Table 4. If any of these works were systematic reviews of the existing literature, then the title, abstract 
and keywords of their references were also analyzed. When it was found relevant, the full text of these references were also considered.

Table 4. Selection Criteria

\begin{tabular}{|l|l|}
\hline$\#$ & Criterion \\
\hline \hline 1 & $\begin{array}{l}\text { Either the full text of the work is available to read on any of the } \\
\text { repositories presented in Table 1 or was made available by its authors when } \\
\text { contacted }\end{array}$ \\
\hline 2 & $\begin{array}{l}\text { The work discusses, compares or evaluates concepts, methods, tools and } \\
\text { techniques related to the public sector }\end{array}$ \\
\hline
\end{tabular}

It is worth mentioning that the selection criteria described in Table 4 restrict the search for relevant work to those related to the public sector. This is consistent with the goals that have been set at the beginning of this paper.

\subsection{Works Submitted to the Selection Criteria}

Among the works submitted to the selection criteria, [31] and [32] propose the use of frameworks for analyzing ICT investments. The first is based on the idea that technology readiness assessment (TRA) plays an important role in the value creation of ICT projects [33]. This particular work provides the necessary means to estimate the economic benefits of TRA analysis, which can then be inputted into traditional valuation techniques such as NPV, ROI and real options.

The second advocates that not every ICT project needs to have their return on investment estimated. Furthermore, not every ICT project has to be aligned with business strategy. Therefore, the proposed framework others a new perspective on the meaning of ICT strategy, at the same time that indicating what applications should be provided to business and when they should be made available.

When analyzing agile software projects Cao et al. present a set of practices to handle the conflicting demands that are raised by using traditional funding methods to run this type of initiative [34]. Most frequently, these conflicts arise when trying to deal in the traditional way with questions that the agile methods can only provide answers to at the end of the development process. For instance,

- When can we expect to have the functional requirements completely identified?

- When are the non-functional requirements going to be entirely implemented?

- When are the project's scope, schedule and cost going to be fully estimated?

- When will we be able to come up with a detailed plan to run the project?

- Etc.

Milavov \& Njegus [35] analyze the business value provided by a number of software development teams that have adopted agile methods. Wattrus [36], Steindl [37], Harris et al. [38] as well as Milavov \& Njegus (op. cit.) suggest that intangible benefits should be translated into financial amounts, so that they can be used for ROI calculation. However, none of these authors presents details on how this should be done. The practice of turning intangible benefits into tangible financial amounts is opposed to the ideas of [32], who states that intangible benefits should be included in the project's business case as what they really are, i.e. subjective perceptions of reality [4].

Having intangible benefits included in ICT business cases is an idea also suggested by [39] and [40]. However, none of them proposes a method to either analyze or quantify such benefits. They suggest that intangible benefits should be treated subjectively and informally.

Al-Khouri [41] in his book "Critical Thoughts from a Government Perspective" argues that ICT projects in the public sector tends to be unsuccessful when their investment analysis is solely based on ROI. He asserts the ROI's inability to deal properly with intangible benefits and risks. These ideas are also supported by 
[42]. One should be aware that Al-Khouri uses the term agile to refer to concepts that bear no relationship to agile methodologies.

Lappo \& Andrew [43] present a technique to evaluate the agility of software development teams that use $\mathrm{XP}$ and Scrum. In their work, Lappo \& Andrew do not discuss investment analysis techniques nor discuss intangible benefits yielded by agile projects. Their work may appeal more strongly to those involved with the improvement of the software development process.

Sachs [44], Pather et al. [45], Khurum [46], Harris et al. [47], Barclay [48] and Gentle [49] comment on the challenges and difficulties of dealing with intangible benefits when evaluating ICT projects. None of these authors discuss them management of technology projects in the public sector nor suggest methods to analyze intangible benefits. Khurum (op. cit.) cites the Incremental Funding Method (IFM) [50] as an approach that is capable of dealing with intangible benefits in the requirements selection phase and also in the release planning phase.

When discussing the impact of e-gov projects on public administration and society, Titah \& Barki [51] highlight the importance of taking into account both tangible and intangible benefits. Nevertheless, they do not discuss how this could be achieved.

By proposing a multidimensional model to assess the business value of agile software projects, Rusnjak [52] recognizes the importance of intangible benefits to enable better requirements prioritization and enhanced focus on strategic goals. Nevertheless, in his work Rusnjak neither suggests how intangibles should be evaluated nor considers the distinctive role they play in the development of software in the public sector [4].

Hidding \& Nicholas [53] analyze management principles that contribute to the success of ICT projects. According to these researchers, despite running over budget or taking longer than expected, ICT projects can still be perceived as a success.

The main reason of this apparently contradictory aspect of project management valuation is the intangible benefits, which are not considered by the traditional management criteria. See the PMI's Project Management Body of Knowledge in this respect [54].

In their work, these authors propose a new project management paradigm called Value-Driven Change Leadership (VDCL), which takes into consideration the value of both tangible and intangible benefits.

Barclay [48] also recognizes the deficiency of traditional assessment methods, which are based on cost, time and scope. To overcome the shortcomings of traditional assessment methods of information system projects, Barclay advocates the use of project performance scorecards, which connects tangible and intangible benefits to business strategy.

According to Biffl et al. the main source of uncertainty when determining the economic value of a software project is the intangible benefits they provide, which are hard to quantify in financial terms [55]. The authors suggest the use of decision trees and real options techniques to deal with these uncertainties. However, no details are provided on how to assess the value of intangible benefits nor on how to deal with the uncertain aspects of project valuation.

Akker et al. [56] present a method to help software developers to determine the next set of features to be implemented in a software project. The method takes into consideration that the ideal set of features is the one that maximizes project revenue. Also, it takes into account that some features cannot be implemented straight away due to lack of resources and dependency relations that naturally occur among them. Although the authors recognize that revenue stems from the tangible and intangible benefits provided by the software project, the valuation of intangibles is not considered in the proposed method.

\subsection{Search Strategy Summary}

A summary of the search strategy used in this paper is presented in Fig. 1, which includes the number of 
selected and discarded references in each step of the search strategy outlined in the literature review. Note that in the end all works were eliminated. Therefore, after analyzing over 500 works from 9 database sources there was no work presenting a method for the evaluation of agile software projects in the public sector that deals with intangible benefits.

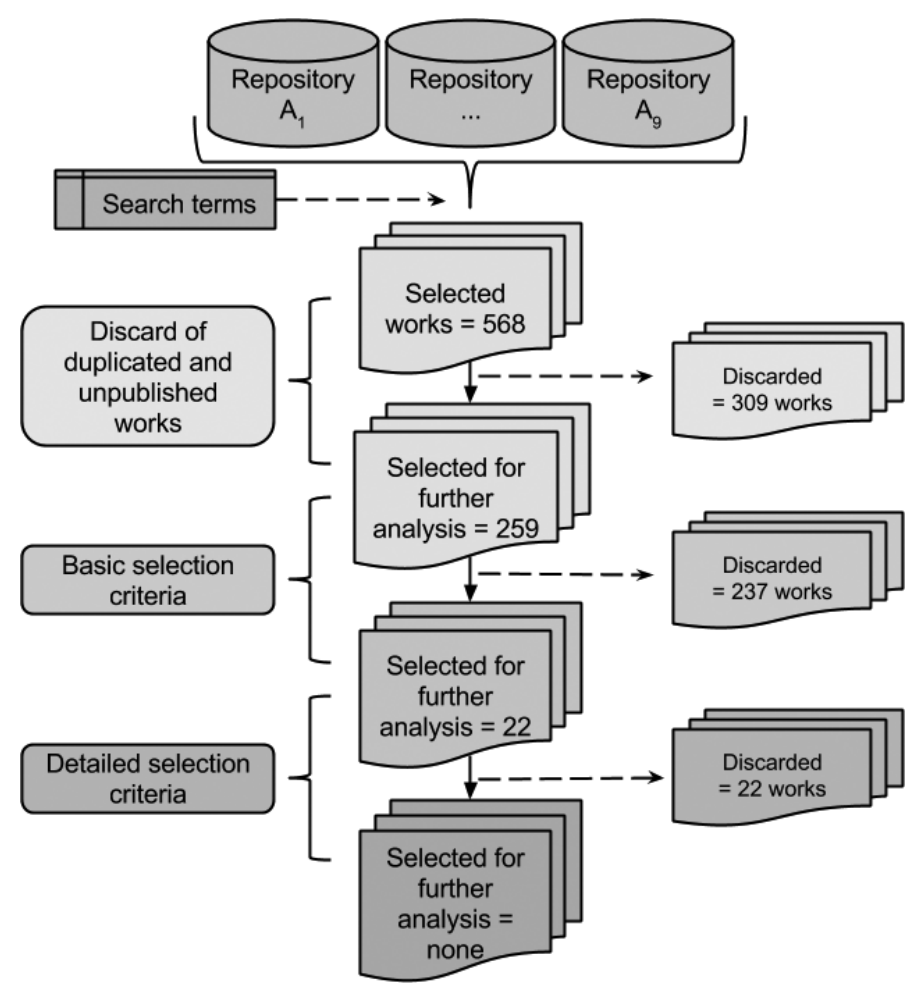

Fig. 1. Search strategy summary.

\section{Research Opportunities}

The absence of proposals that address this subject indicates the existence of a significant gap in practical and theoretical research. Government is one of the major investors in software development. Moreover, agile methods have been gaining popularity as the preferred paradigm for software development in public organizations [57].

There are at least four dimensions regarding the evaluation of agile software projects in the public sector that present opportunities for research and development, i.e. the incremental funding of projects, project evaluation under uncertainty, investment efficiency and maximization of the appropriation of intangible benefits.

\subsection{Incremental Funding of Projects}

The Incremental Funding Method (IFM) is a financially based approach for analyzing investments in software projects. The IFM is the work of Denne \& Cleland-Huang [50]. It uses the ideas of Chang et al. [58] on the functional decomposition of classes of objects to partition software to be developed in modules. These modules have low coupling and high internal cohesion.

According to Denne \& Cleland-Huang [50] it is often the case that software systems can be divided into two kinds of modules. The first provides financial returns as soon as it is made available for use. The second provides no financial returns, but allows for the development of other modules and system parts. Denne and Cleland-Huang have called the former minimum marketable features (MMFs) and the latter architectural elements (AEs). 
The order in which MMFs and AEs are developed can considerably alter the value generated by software projects. In addition, it impacts on other financial indicators such as capital investment, ROI, self-funding point and break-even point [59].

As a result the ideas of Denne \& Cleland-Huang on incremental funding can make software projects cheaper to run and less risky from the financial point of view [60]. Nevertheless, so far no proposals have been put forward to allow agile software projects in the public sector to be divided into MMFs and AEs.

As a consequence, the financial returns provided by a MMF cannot be used to finance the development of other system parts. Moreover, agile software projects in the public sector tend to require more capital investment than they should. In addition, the savings that could have been provided by these projects cannot be used to run other projects, which could further benefit the general public.

\subsection{Project Evaluation under Uncertainty}

Many methods that deal with the evaluation of agile software projects require decision makers to provide precise estimates of their value, complexity and risk. However, according to Werner Heisenberg (1901-1976), the celebrated German physicist, the future cannot be forecasted with precision [61].

Therefore, by ignoring the uncertainties that naturally exist in regard to future value estimates, these methods tend not to describe reality as it really is. Hence, the situations in which they can be successfully used are limited.

All of this puts decision makers in the public sector in a very difficult position when trying to decide where and when to invest taxpayers' money. Their lives would be made easier by the development of evaluation methods that embrace the uncertainties that naturally surround agile software projects.

\subsection{Investment Efficiency}

In process engineering a production unit is an arrangement of activities that takes a set of inputs to yield products and services. These can be used as inputs for other production units or consumed by end users. The productivity of a unit $U$ is given by:

$$
\operatorname{Productivity}_{U}=\frac{\text { Output }_{U}}{\operatorname{Input}_{U}}
$$

It should be pointed out that the less input a production unit takes to yield the same amount of products and services the better. Also, the greater the amount of output a production unit yields from the same input the better [62].

In this context, efficiency is the upper limit on productivity considering the available technology. Therefore, a production unit is efficient when its productivity cannot be further improved with available technology.

However, in many circumstances, the efficiency of a production unit cannot be determined in absolute terms. In this case, this efficiency is more easily estimated in relative terms, considering other production units of the same kind [63].

For example, imagine a store $S$ in a shopping center. Suppose that its owners are interested in estimating its productivity. Moreover, assume that they have decided to analyze the financial resources that $S$ consumes in regard to the profit that it yields. In this case, they can use Equation 1 and divide one value by the other.

Nevertheless, without a well-established standard the store owners would find themselves in a difficult position to decide whether $S$ is efficient or not. However, if they calculate the productivity of all the other stores in the same shopping center, then they can calculate the relative efficiency of $S$ in respect to the other stores [62]. 
Obtaining more for less seems to be a common desire among the citizens of any country. As a result, decision makers in the public sector are frequently under pressure to reduce expenditure at the same time as improving the quality of services provided by the government. In other words, they are required to invest taxpayers' money more efficiently.

As the number of agile software projects increases in the public sector, it becomes paramount to have evaluation methods that consider the efficiency of future investments.

\subsection{The Maximization of the Appropriation of Intangible Benefits}

In financial terms, an asset is something of value that can be owned or controlled. For instance, trains, cell phones, houses, shares, club memberships, copyrights, etc. The value of an asset derives from the benefits that it yields to its owner or controller. For example, a car can be sold or rented and the resulting capital can be used to buy products and services, and also to start a new business.

Some of the benefits provided by an asset derive from subjective perceptions of reality. As a result, they have no physical or financial embodiment. These assets are called intangibles [64]. For example, the pride of being accepted in a prestigious educational institution, the satisfaction that comes from helping others and the boost in employee moral that stem from completing an important job, are examples of intangibles benefits that usually require commitment and hard work.

When an investment in ICT is made in the public sector, the chances of having to consider intangible benefits are substantial. Governments are non-profit organizations whose sole purpose is to improve the quality of life of its citizens.

However, many aspects of life quality depends on perceptions of reality. For example, better economic opportunities, superior health care services, improved security and a fairer judicial system are examples of intangible benefits that citizens tend to appreciate.

Government is among the biggest investors in ICT worldwide. Nevertheless, the methods for the evaluation of agile software projects that consider intangibles do not provide the necessary means to maximize their appropriation.

In addition, they do not acknowledge that intangible benefits may increase in worth and also depreciate with the passage of time. Therefore, they fail to model reality at it really is, leading to a negative effect on the effectiveness of decision making. More research need to be done in this regard [65].

\section{Conclusions}

This paper performs a literature review on existing publications to reveal research opportunities on the evaluation of agile software projects in the public sector.

The literature review shows that in recent years many methods, frameworks and models have been put forward to evaluate agile software projects. However, these methods do not acknowledge important aspects of public sector investments.

For example, government is a non-profit organization, whose mission and objectives are centered on people's well-being. Moreover, ICT investments in the public sector tend to yield a myriad of intangible benefits, which have to be take into account when determining their worth. As a result, the number of situations in which these methods, frameworks and models can be successfully used to evaluate initiatives in the public sector is limited.

The literature review also uncovers that so far no work has directly addressed the evaluation of agile software project in government organizations, especially those that yield intangible benefits. It is argued in the paper that this is an important gap in theoretical and practical research. Furthermore, this gap must be filled given the relevance of the subject and the huge amount of taxpayer's money that is invested in ICT annually. 
Finally, four important dimensions of software investment in the public sector are identified for future research and development, i.e. the incremental funding of projects, project evaluation under uncertainty, investment efficiency and maximization of the appropriation of intangible benefits.

\section{References}

[1] Moore, S. (2013). Gartner Says Worldwide Government IT Spending Flat in 2013. Retrieved February 16, 2014, from http://www.gartner.com/newsroom/id/2518815

[2] US government. (2013). Federal IT Spending for Budget Year 2014, Retrieved February 19, 2014, from http://www.itdashboard.gov

[3] Financial times. (2013). 2013 Financial Times Global 500 List, Retrieved February 13, 2014, from http://www.ft.com/indepth/ft500

[4] Alencar, A. J., Fernandes, R. P., Schmitz, E. A., \& Schmitz, A. L. C. (2013). Maximizing the appropriation of the intangible benefits yielded by it investments in the public sector. Journal of Software, 8(7), 1537-1549.

[5] Brown, M. M., \& Garson, G. D. (2013). Public Information Management and E-Government: Policy and Issues.

[6] Rouhani, S., Asgari, S. S., \& Mirhosseini, V. (2012). Review study: Business intelligence concepts and approaches. American Journal of Scientific Research, 62-75.

[7] Wood, D. (2014). Linking Government Data, Springer.

[8] Timmer, M. P., \& Ark, B. V. (2005). Does information and communication technology drive EU-US productivity growth differentials? Oxford Economic Papers, 57(4), 693-716.

[9] Wernham, B. (2012). Agile Project Management for Government - Leadership Skills for Implementation of large-scale Public Sector Projects in Months Not Years. Maitland and Strong.

[10] Gorans, P., \& Kruchten, P. (2014). Agile and Lean Office: Key to Increasing Profit and Employee/Customer Satisfaction, 2nd Edition, IBM Center for the Business of Government.

[11] US government accountability office, software development - Effective practices and federal challenges in applying agile methods. Retrieved March 15, 2014, from http://www.gao.gov/assets/600/593091.pdf

[12] UK cabinet office. Government ICT strategy. Retrieved February 15, 2014, from http://www.gov.uk/government/uploads

[13] Simmons, R. T. (2011). Beyond Politics: The Roots of Government Failure.

[14] Bekkers, V., \& Homburg, V. (2007). The myths of e-government: Looking beyond the assumptions of a new and better government. The Information Society, 23(5), 373-382.

[15] Saunders, A. (2010). Valuing IT-related intangible capital. Proceedings of the International Conference on Information Systems Association for Information Systems.

[16] Rosacker, K. M., \& Rosacker, R. E. (2010). Information technology project management within public sector organizations. Journal of Enterprise Information Management, 23(5), 587-594.

[17] Campbell, J., McDonald, C., \& Sethibe, T. Public and private sector IT governance: Identifying contextual dierences. Australasian Journal of Information Systems, 16(2).

[18] Peers, K., \& Santos, B. L. D. (2013). Research opportunities in information technology funding and system justification. European Journal of Information Systems, 22(2), 131-138.

[19] Balter, B. J. (2011). Towards a more agile government: The case for rebooting federal IT procurement. Public Contract Law Journal, 41(1), 149.

[20] Abbas, N., Gravell, A. M., \& Wills, G. B. (2008). Historical roots of agile methods: Where did "agile thinking" come from? Agile Processes in Software Engineering and Extreme Programming, 94-103. 
[21] Beck, K., Cunningham, W., Fowler, M., Jeries, R., Schwaber, K., Sutherland, J., Beedle, M., Bennekum, A. V., Cockburn, A., Grenning, J., Highsmith, J., Hunt, A., Kern, J., Marick, B., Martin, R. C., Mellor, S., \& Thomas, D. (2001). Twelve Principles of Agile Software. Retrieved March 15, 2014, from http://agilemanifesto.org/principles.html

[22] Petersen, K., \& Wohlin, C. (2009). A comparison of issues and advantages in agile and incremental development between state of the art and an industrial case. Journal of Systems and Software, 82(9), 1479-1490.

[23] Gough, D., Oliver, S., \& Thomas, J. (2013). An Introduction to Systematic Reviews. SAGE Publications.

[24] Higgins, J. P. T., \& Green, S. (2011). Cochrane Handbook for Systematic Reviews of Interventions, 2nd Edition, Wiley.

[25] López-Cózar, E., Robinson-García, D. N., \& Torres-Salinas, D. The google scholar experiment: How to index false papers and manipulate bibliometric indicators. Journal of the Association for Information Science and Technology, 65(3).

[26] Masli, A., Richardson, V. J., J. Sanchez, M., \& Smith, R. E. (2014). The interrelationships between information technology spending, CEO equity incentives and firm value. Journal of Information Systems, 28,134-145.

[27] Spiezia, V. (2012). ICT investments and productivity: Measuring the contribution of ICTS to growth. OECD Journal: Economic Studies, 6(1), 199-211.

[28] Kleis, L., Chwelos, P., Ramirez, R. V., \& Cockburn, I. (2012). Information technology and intangible output: The impact of it investment on innovation productivity. Information Systems Research, 23(1), 42-59.

[29] Kautz, K., Johansen, T., \& Uldahl, A. (2014). Creating business value through agile project management and information systems development: The perceived impact of Scrum. Proceedings of the International Conference on Transfer and Diffusion of IT (pp. 150-165).

[30] Uyar, A. (2009). Google stemming mechanisms. Journal of Information Science, 35(5), 499-514.

[31] Bailey, R. U., Mazzuchi, T. A., Sarkani, S., \& Rico, D. F. (2014). A Model for Evaluating the ROI of Technology readiness assessments, Department of Engineering Management and Systems Engineering. Retrieved March 15, 2014, from http://davidfrico.com/roi-of-tras.pdf

[32] Barnes, A. (2010). A New Framework for IT Investment Decisions: A Practical Guide to Assessing the True Value of IT Projects in Business. Harriman House.

[33] Krahn, S., Sutter, H., \& Johnson, H. (2013). New developments in the technology readiness assessment process. Proceedings of the Waste Management Conference on the International Atomic Energy Agency (IAEA) and The International Nuclear Information System (INIS).

[34] Cao, L., Mohan, K., Ramesh, B., \& Sarkar, S. (2013). Adapting funding processes for agile IT projects: An empirical investigation. European Journal of Information Systems, 22(2), 191-205.

[35] Milanov, G., \& Njegus, A. Analysis of return on investment in different types of agile software development project teams. Informatica Economica, 16(4).

[36] Wattrus, A. (2014). Benefit realisation lifecycle MANAGEMENT in IT-related business projects. Ph.D. thesis, Witwatersrand University, Faculty of Engineering, Johannesburg, South Africa. Retrieved March 15, 2014, from http://wiredspace.wits.ac.za//handle/10539/8164

[37] Steindl, C. (2005). From agile software development to agile businesses. Proceedings of the 31 st EUROMICRO Conference on Software Engineering and Advanced Applications (pp. 258-265).

[38] Harris, M. D., Herron, D., \& Iwanicki, S. (2008). The Business Value of IT: Managing Risks, OPTIMIZING Performance and Measuring Results.

[39] Leybourn, E. (2013). Directing The Agile Organisation: A Lean Approach to Business Management. IT 
Governance Publishing.

[40] Adusumilli, S. (2011). IT Strategy and Governance Explained. Sri Adusumilli.

[41] Al-Khouri, A. M. (2013). Critical Thoughts From A Government Perspective. Chartridge Books Oxford.

[42] Avgerou, C. (2011). Information Systems Development and Management. University of London Publishing.

[43] Lappo, P., \& Andrew, H. C. T. (2004). Assessing agility, extreme programming and agile processes in software engineering. Lecture Notes in Computer Science Number 3092, Springer.

[44] Sachs, I. (2011). Performance Driven IT Management: Five Practical Steps to Business Success. Government Institutes.

[45] Pather, S., Remenyi, B., \& Remenyi, D. (2011). Managing Risks of ICT Projects, Academic Publishing International Ltd.

[46] Khurum, M. (2011). Decision support for product management of software intensive products. Ph.D. thesis, Blekinge Institute of Technology, School of Computing, Karlskrona, Sweden.

[47] Harris, M. D., Herron, D., \& Iwanicki, S. (2008). The Business Value of IT: Managing Risks, Optimizing Performance and Measuring Results. Auerbach Publication.

[48] Barclay, C. (2008). Towards an integrated measurement of IS project performance: The project performance scorecard. Information Systems Frontiers, 10(3), 331-345.

[49] Gentle, M. (2007). IT SUCCESS!: Towards a New Model for Information Technology, John Wiley \& Sons.

[50] Denne, M., \& Cleland-Huang, J. (2004). The incremental funding method: Datadriven software development. Software, 21(3), 39-47.

[51] Titah, R., \& Barki, H. (2006). E-government adoption and acceptance: A literature review. International Journal of Electronic Government Research, 2(3), 23-57.

[52] Rusnjak, A. (2010). Improving IT-strategy-alignment and requirements engineering with a multi-dimensional business value. Proceedings of the 16th International Working Conference on Requirements Engineering: Foundation for Software Quality.

[53] Nicholas, J., \& Hidding, G. Management principles associated with IT project success. International Journal of Management and Information Systems, 14(5).

[54] PMI. A Guide to the Project Management Body of Knowledge (PMBOK), 5th Edition, Project Management Institute.

[55] Biffl, S., Aurum, A., Boehm, B., \& Erdogmus, H. P. (2006). Value-Based Software Engineering. Springer.

[56] Akker, M. V. D., Brinkkemper, S., Diepen, G., \& Versendaal, J. (2008). Software product release planning through optimization and what-if analysis. Information and Software Technology, 50(1-2), 101-111.

[57] Bustard, D., Wilkie, G., \& Greer, D. (2013). The maturation of agile software development principles and practice: Observations on successive industrial studies in 2010 and 2012. Proceedings of the 20th Annual IEEE International Conference and Workshops on the Engineering of Computer Based Systems (ECBS) (pp. 139-146).

[58] Chang, C. K., Cleland-Huang, J., Hua, S., \& Kuntzmann-Combelles, A. (2001). Function-class decomposition: A hybrid software engineering method. Computer, 34(12), 87-93.

[59] Cleland-Huang, J. (2005). Financially informed requirements prioritization. Proceedings of the International Conference on Software Engineering (ICSE)(pp. 15-21).

[60] Alencar, A. J., Jr., J. V. D., Schmitz, E. A., Correa, A. L., Jr., I. M. V. (2012). On the merits and pitfalls of the incremental funding method and its software project scheduling algorithms. Communications in Computer and Information Science, 493-502.

[61] Lindley, D. (2008). Uncertainty: Einstein, Heisenberg, Bohr, and the Struggle for the Soul of Science.

[62] Cook, W. D., Tone, K., \& Zhu, J. (2014). Data envelopment analysis: Prior to choosing a model. 
[63] Charles, V., \& Kumar, M. (2012). Data Envelopment Analysis and Its Applications to Management, Cambridge Scholars Publishing.

[64] Zéghal, D., \& Maaloul, A. (2011). The accounting treatment of intangibles - A critical review of the literature. Accounting Forum, 35(4), 262-274.

[65] Rezaee, Z. (2011). Financial Services Firms: Governance, Regulations, Valuations, Mergers, and Acquisitions. Wiley.

Marcelo Carvalho Fernandes is a Ph.D. student with the Federal University of Rio de Janeiro (UFRJ), Brazil. He holds a B.Sc. and M.Sc. in computer science from UFRJ. His research interests include agile software development methodologies and economics of software engineering.

Antonio Juarez Alencar is a researcher with the Federal University of Rio de Janeiro (UFRJ), Brazil. He received his B.Sc. in mathematics and M.Sc. in system engineering and computer science from UFRJ. He holds a D.Phil. in computer science from Oxford University, England. His research interests include economics of software engineering, IT strategy and risk analysis.

Eber Assis Schmitz is a professor of computer science with the Federal University of Rio de Janeiro (UFRJ). He holds a B.Sc. in electrical engineering from the Federal University of Rio Grande do Sul (UFRGS), an M.Sc. in electrical engineering from the Federal University of Rio de Janeiro and a Ph.D. in computer science and control from the Imperial College of Science, Technology and Medicine, London, England. His research interests include software development modeling tools, business process modeling and stochastic modeling.

Monica Ferreira da Silva is a researcher with the Federal University of Rio de Janeiro (UFRJ), Brazil. She received her B.Sc. in mathematics and M.Sc. in system engineering and Computer Science from UFRJ. She holds a Ph.D. in business administration from the UFRJ's School of Business. Her research interests include the adoption of technology and IT strategy.

Petros Sotirios Stefaneas is a researcher with the Department of Mathematics of the National Technical University, Athens, Greece. At NTUA he coordinates the activities of the logic and formal methods group of the Algorithm Applications and Logic Laboratory. His research interests include logic and formal methods, philosophy of computer science and software verification. 